\title{
Schwarzhaariges Mädchen
}

\section{Schieles schamlose Erotik}

\begin{abstract}
Der 1918 mit nur 28 Jahren gestorbene
Egon Schiele gehörte zu jenen Künstlern, deren

Werke die Nazis mit ganz besonderem Hass als

„entartet" denunzierten. Heute gilt er neben

Gustav Klimt und Oskar Kokoschka als bedeu-
\end{abstract}

tendster Maler der Wiener Moderne. Mit Klimt, der

für ihn eine Art Ziehvater wurde, verband Schiele

eine lebenslange Freundschaft. Beide teilten ein

Interesse für die Sexualität und den nackten

menschlichen Körper. Und beide setzten sich mit

diesen Themen auf eine Art und Weise auseinander, die unterschiedlicher nicht sein könnte.

K limt betreibt als typischer „Art-Nouveau-Maler" einen Kult der Schönheit. Seine zumeist dem Großbürgertum entstammenden Modelle vergoldet er solange, bis nur noch Kopf und Hände aus den Bildern herausschauen, während sich die Körper in üppigen Ornamenten verlieren. Er ist der Maler der Belle Etage. Ganz anders Schiele. Er steigt hinab in die Kellergewölbe und Abgründe, reißt die Dekoration herunter und stößt dabei auf nackte Körper, die nur in wenigen Fällen anziehend sind. Fast kann man von einer systematischen „Verhässlichung“ seiner Modelle sprechen.

Schiele bleibt dabei auch als Maler immer Zeichner. Mit dünnem, beinahe messerscharfem Strich verleiht er seinen Körpern harte Konturen. Die normalerweise weichen weiblichen Rundungen werden bei ihm ins Eckige übersetzt. Häufig sind seine Gestalten verzerrt oder verrenkt, haben etwas Ausgezehrtes, ihre Gelenke sind entzündet oder geschwollen. Eine Umgebung, in die sie eingebettet sind, fehlt zumeist völlig. Schiele setzt seine Akte bevorzugt auf eine leere, homogene Fläche.

Revolutionär neu in seinen Bildern ist die offensichtliche Zurschaustellung des Geschlechtlichen. Bis dahin war es in der Kunstgeschichte allgemein üblich, die primären Geschlechtsorgane auszusparen oder zumindest zu kaschieren. Bei Schiele rücken sie nun ins Zentrum der Darstellung, und nicht selten werden sie noch farblich betont. Die Tatsache, dass er die Scham so häufig und drastisch zeigt, brachte ihm früh den Vorwurf ein „schamlos“ zu sein.

Ist Schiele nun also ein Pornograf? Für seine Zeitgenossen war er das sicher. Und zwar nicht nur in einem ästhetischen sondern auch in einem juristischen Sinn. Wegen „Verbreitung unsittlicher Zeichnungen" wurde er 1912 verhaftet und zu einer kurzen Gefängnisstrafe verurteilt. Dennoch ist Pornografie per Definition „die

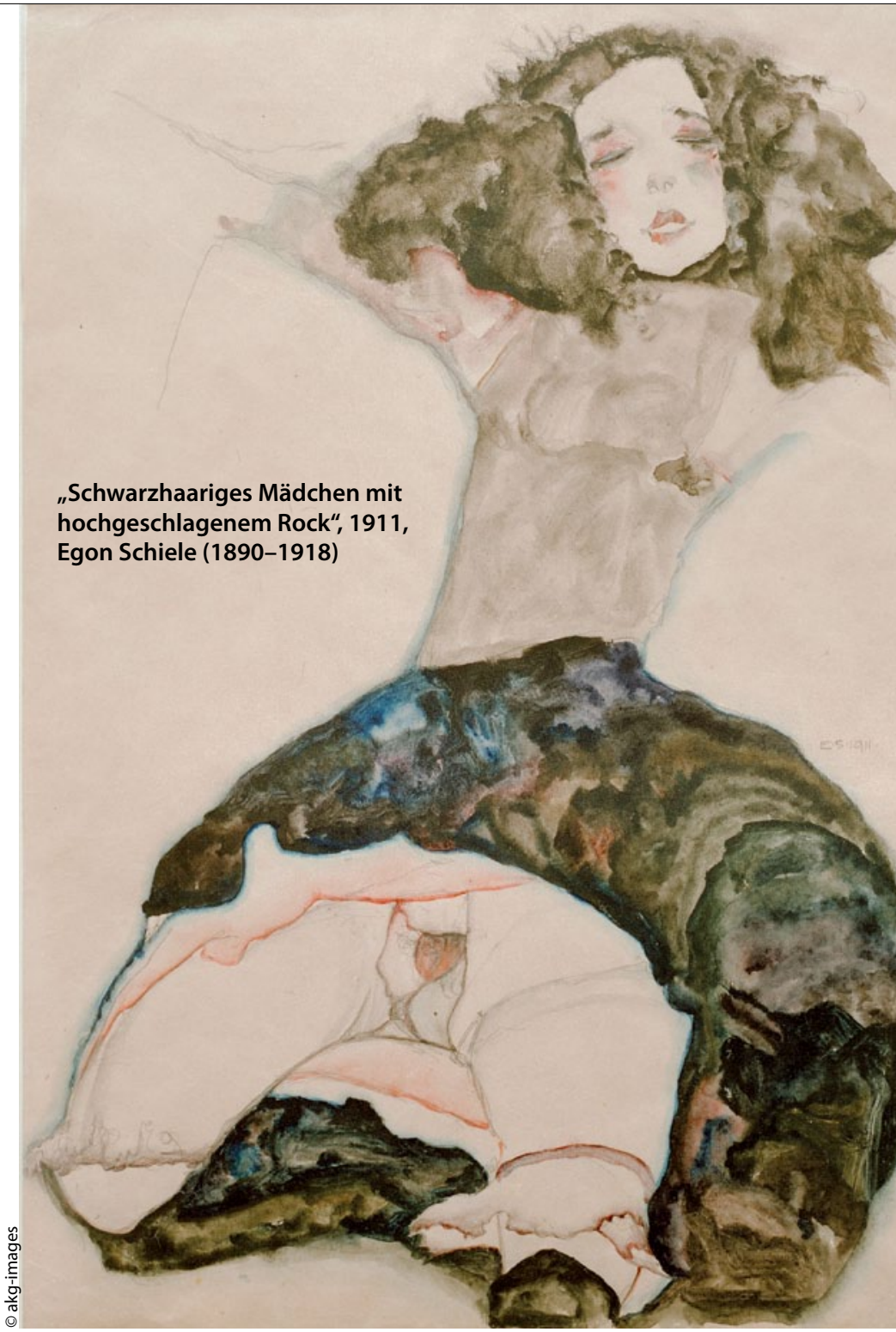

Darstellung von Nacktheit zum Zweck der sexuellen Erregung". In diesem Sinne ist wohl eher die schwülstige Jugendstilerotik mit ihren zur Kunst sublimierten Männerphantasien pornografisch. Schieles Modelle sehen dagegen so gar nicht verführerisch, so gar nicht lüstern aus. Sexualität wird als menschlicher Trieb dargestellt, aber eher als ein Trieb, an dem man leidet. Der menschliche Körper produziert nicht sinnliches Begehren, vielmehr Schrecken und Qual. Zur Pornografie taugt das so wenig wie die mit Eiseskälte beschriebenen Sexualakte in den Romanen von Michel Houellebecq.

Das Werk Egon Schieles drohte nach der Bildstürmerei der Nazis und der Prüderie der Nachkriegsjahre fast in Vergessenheit zu geraten. Dass Schiele heute zu den wichtigsten Vertretern des österreichischen Expressionismus zählt, verdanken wir in erster Linie einem Mediziner. Der Wiener Augenarzt Rudolf Leopold kaufte bereits früh mit großem Sachverstand und in großem Stil die Arbeiten seines Landsmannes. Seine beeindruckende Sammlung vermachte er 1990 dem Staat. Im Museum Leopold des Wiener Museumsquartiers befindet sich heute die mit Abstand größte Auswahl der Werke Schieles. Gut, wenn Augenärzte auch ein gutes Auge für die Kunst haben.

Prof. Dr. med. B. Kleine-Gunk 